\title{
A Pilot Study Examining the Online Behavior of Web Users with Visual Impairments
}

\author{
Julian Brinkley \\ Department of Computer Science \\ East Carolina University \\ Greenville, North Carolina
}

\author{
Nasseh Tabrizi \\ Department of Computer Science \\ East Carolina University \\ Greenville, North Carolina
}

\begin{abstract}
Thisreport presents the results of a pilot study on the online behavioral habits of 46 internet users; 26 of whom self-identified as having a visual impairment (either blind or low vision). While significant research exists which documents the degree of difficulty that users with visual impairments have in interacting with the Web relative to the sighted, few have addressed the degree to which this usability disparity impacts online behavior; information seeking and online exploratory behaviors especially. Fewer still have addressed this usability disparity within the context of distinct website types; i.e. are usability issues more pronounced with certain categories of websites as opposed to others? This pilot study was effective both in exploring these issues and in identifying the accessibility of online social networks as a primary topic of investigation with respect to the formal study that is to follow.
\end{abstract}

Keywords-Web Accessibility; Social Networking; Human Computer Interaction

\section{INTRODUCTION}

Given that the modern World Wide Web is a largely visual medium, it would stand to reason that some usability disparity would exist between sighted users of the Web and users with some degree of blindness. This contention is further bolstered by the fact that these visually impaired users, by virtue of the nature of their disability, typically access the Web using a broad spectrum of specialized accessibility technologies with a number of documented deficiencies [1-4]. While the quantification of this disparity varies, several studies have indicated that the Web is roughly three times more difficult to use for individuals with visual impairments than it is for sighted users [4,5]. Few studies however have directly addressed the degree to which this problem effects the online behavior of users with visual impairments. As a result, several subsequent questions regarding the online behavioral patterns of these users are left unanswered, questions which serve as the core of our research effort:

1) Are the types of usability issues faced by individuals with visual impairments largely universal or do they vary depending upon the website type in question?

2) Do individuals with visual impairments avoid new or unfamiliar websites due to fears regarding ease of use and accessibility?

3) What impact do these issues have on these users' participation in highly interactive online social networks?

As a preliminary exercise to conducting a more formal study to investigate the aforementioned behavioral questions a pilot study was conducted using an online questionnaire. This questionnaire was administered to 46 sighted, low vision and blind internet users age 18 and older. Participants were surveyed in an attempt to provide answers to online behavioral and accessibility questions while also providing investigative direction in preparation for a more exhaustive and detailed study.

\section{BACKGROUND}

\section{A. Visual Impairment}

For the purposes of this research individuals identified as having a visual impairment should be interpreted as those with a visual disability that is not correctable by traditional assistive devices up to and including full blindness [6]. Those individuals identified as "sighted" should be viewed as those having vision in the normal range or correctable to the normal range using traditional assistive devices like glasses or contact lenses.

\section{B. Website Usability versus Accessibility}

The terms accessibility and usability are often used inconsistently, interchangeably and in an occasionally overlapping manner in accessibility research. Given that they are not used interchangeably within this report and significant literature exists which outlines their appropriate use, a brief explanation of their use within this report is provided. Accessibility [7-9] is used to describe the ability of users with visual disabilities to functionally interact with a website whereas usability [10] is used to describe the qualitative characteristics of this interaction.

\section{PILOT STUdY}

\section{A. Participants}

A convenience sample of 46 individuals participated in the pilot study, the composition of which is outlined in Table 1. Of the 46 participants, 25 (18 men and 7 women) were categorized as having some type of visual impairment; the remaining 21 participants (6 men and 15 women) were identified as "sighted".

While research involving the general population typically requires a representative sample of 20-30 participants at a minimum, it is generally acceptable for Human-Computer Interaction $(\mathrm{HCI})$ research involving users with disabilities to have as few as 5-10 participants in some cases[11]. In the case of individuals with significant visual impairments issues with 
physical mobility, chiefly lack of transportation and scheduling difficulties, have been well documented as barriers to study participation [11]. These individuals often utilize any number of specialized Web browsers or screen reading applications with personalized configurations, therefore the ability to precisely duplicate a specific user's configuration in its totality within a research setting has its difficulties; an issue which exacerbates the aforementioned mobility problem. Distributed research methods, like online questionnaires, have a number of attractive qualities within the context of usability research involving disabled populations. While there may exist some trade off in terms of study control relative to direct observation or interview, the added convenience of distributed research methods may potentially increase participation by eliminating roadblocks to participation. As a result, distributed research methods like diaries or surveys are often ideal tools for HCI research involving these users. These methods allow participation using accessibility configurations that are most familiar to the participants as well as participation at a time and location of the greatest convenience. Recognizing these factors an online questionnaire was chosen for this study.

Participants were recruited through the assistance of organizations for individuals with visual impairments and through posts on the social networking website Facebook (http://www.facebook.com/). In the case of the former, study information was distributed via email to the respective membership of the National Association of Blind Students (NABS), the North Carolina Association of Blind Students (NCABS) and the Massachusetts Association of Blind Students (MABS); with the assistance of each organization's respective leadership. Each e-mail contained a detailed description of the study, consent information and a clickable text hyper-link to the online questionnaire. In the latter case, distribution via online social network, this same explanatory and consent information was made available with a text hyperlink to the online questionnaire using a Facebook page administered by the authors. The study protocol was approved by the East Carolina University, University and Medical Center Institutional Review Board (UMCIRB).

While a large, more representative sample would have been preferable, it was determined that a convenience sample of as few as 10 participants with visual impairments was acceptable in this initial phase of the research effort. 25 individuals with visual impairments ultimately participated in the study however. The added complexity and expense of random sampling with a large number of participants was deemed unnecessary for this preliminary work given that this study was conducted as much for investigative direction and experience conducting HCI research with disabled participants as it was for the data to be collected. In our subsequent formal study sample sizes and selection methods will be modified with the goal of selecting a sample that is likely more representative of the target population.
TABLE I. BREAKDOWN OF STUDY PARTICIPANTS

\begin{tabular}{|c|l|l|l|l|l|l|}
\hline \multirow{2}{*}{ Participants } & \multicolumn{2}{|l|}{ Sighted } & \multicolumn{2}{l|}{$\begin{array}{l}\text { Visually } \\
\text { Impaired }\end{array}$} & \multicolumn{2}{l|}{ Combined } \\
\cline { 2 - 8 } & $\%$ & Number & $\%$ & Number & $\%$ & Number \\
\hline Sex & & & & & & \\
\hline Male & 29 & 6 & 72 & 18 & 52 & 24 \\
\hline Female & 71 & 15 & 28 & 7 & 48 & 22 \\
\hline Age & & & & & & \\
\hline 18 to 25 & 58 & 12 & 48 & 12 & 52 & 24 \\
\hline 26 to 35 & 19 & 4 & 8 & 2 & 13 & 6 \\
\hline 36 or & 23 & 5 & 44 & 11 & 35 & 16 \\
older & & & & & & \\
\hline
\end{tabular}

\section{B. Procedure}

A 33 question, mixed type, online questionnaire was developed which also included user ratings with 5 point Likerttype items ( 1 = strongly disagree, 2 = somewhat disagree, $3=$ neutral, $4=$ somewhat agree, $5=$ strongly agree) [12]. In addition to collecting demographic information, questions focused specifically on participants' online exploratory behavior, Web usage habits, general opinion of Web usability, opinions regarding website interactivity and use of online social networking applications. Some emphasis was given to social networking within the study given the rise of social networking applications and the increasing incorporation of social networking capabilities to all manner of websites. Five (5) questions within the study addressed social networking specifically.

\section{PRELIMINARY RESUltS}

\section{A. Information Seeking and Exploratory Behavior}

Tables 2 and 3 provide a comparison of the information seeking and online exploratory behavior of both the sighted and visually impaired participant groups. Overall, both groups felt that they could relatively easily find what they were looking for online as expressed within a series of 5 point Likert-type items ( $1=$ strongly disagree to $5=$ strongly agree $)$. However this feeling of ease was more pronounced in sighted participants than with the visually impaired group. While both groups felt that most websites are easy to navigate (visually impaired $\mathrm{M}=3.86$, Mode = 4; sighted $\mathrm{M}=4.14$, Mode = 4), the visually impaired group expressed a strong desire for a Web that is easier to use $(\mathrm{M}=3.59, \mathrm{SD}=1.43$, Mode = 4) whereas the sighted group expressed general satisfaction with current levels of Web usability $(\mathrm{M}=2.38, \mathrm{SD}=1.20$, Mode $=$ $1,2)$.

The visually impaired group visited a greater number of websites on a daily basis than sighted participants with $44 \%$ of the visually impaired group indicating that they visited " 11 or more" websites on a daily basis compared to $5 \%$ of the sighted group. 
Users with visual impairments also visited more new websites on a daily basis than the sighted group with $80 \%$ of participants with visual impairments visiting between 1 and 10 new websites daily compared to $67 \%$ of the sighted group. The visually impaired group however expressed some difficulties navigating these new websites $(\mathrm{M}=3.04, \mathrm{SD}=1.33$, Mode $=$ 4) whereas the sighted group expressed minimal difficulty in this regard $(\mathrm{M}=2.43, \mathrm{SD}=1.21$, Mode $=1,3)$.

Both groups expressed minimal website avoidance behavior with fewer than $5 \%$ of both groups indicating an avoidance of new websites. While the visually impaired group indicated significantly more comfort with familiar websites (M $=4.22, \mathrm{SD}=1.11$, Mode $=5$ ) relative to the sighted participants group $(\mathrm{M}=3.57, \mathrm{SD}=0.87$, Mode $=3,4)$, visually impaired participants $(\mathrm{M}=2.00, \mathrm{SD}=1.38$, Mode $=1)$ expressed a comparable and minimal avoidance of new websites due to apprehension regarding the ability to find information of interest. Sighted participants $(\mathrm{M}=2.19, \mathrm{SD}=$ 1.25 , Mode $=1$ ) indicated a slightly greater avoidance of new websites due to these information seeking concerns though both groups indicated that this apprehension did not result in an outright avoidance of new websites. Both groups indicated a significant reliance on search engines for new content with $52 \%$ of sighted participants and $66 \%$ of visually impaired participants identifying this as a primary source of new stories, videos and images. However social networking websites were a significantly more popular source of this information for sighted individuals (33\%) than for the visually impaired group $(13 \%)$.

\section{B. Participants' Website Usage Habits}

Table 4 provides a comparison of website usage habits by website type. Of the nine website types provides, both visually impaired (33\%) and sighted (52\%) participants indicated that social networking websites were the most visited. This number was significantly higher for sighted participants than for the participants with visual impairments however. Sighted participants expressed the most difficulty using Web-logs or "Blogs" (13\%) whereas social networking websites $(21 \%)$ were identified as the most difficult to use by those with visual impairments. The most popular response however for both groups when referencing online difficulties was that no difficulties existed relative to most websites $($ sighted $=67 \%$, visually impaired $=42 \%)$.

\section{Use of Online Social Networks}

Table 5 provides a comparison of the use of social networking websites between the visually impaired and sighted participants. While some commonalities were exposed between the two groups overall, the frequency with which online social networks were used, as well as the perceptions regarding the usability of these websites, differed substantially.

A majority of participants in both groups indicated that they held an online social networking account though the social network participation rate for sighted participants (95\%) was significantly higher than for the visually impaired group (67\%). In an open ended question, both groups indicated a preference for Facebook.com with $81 \%$ of sighted participants and $67 \%$ of individuals with visual impairments indicating that it was their most used social networking website. $77 \%$ of these sighted participants indicated a "moderate" to "extreme" frequency of social network usage compared to $42 \%$ of visually impaired participants.

Perceptions regarding the usability of social networking websites differed substantially between the two groups with sighted participants indicating both a greater enjoyment of these websites as well as significantly greater ease of use. $36 \%$ of individuals with visual impairments indicated that they would like to use social networking websites but found them too difficult to use compared to only $10 \%$ of sighted participants.

$72 \%$ of sighted participants indicated some degree of "enjoyment" in their use of online social networks as compared to $41 \%$ of participants with visual impairments. An additional $45 \%$ of the visually impaired users group indicated some degree of dislike of social networking websites compared to $15 \%$ of the sighted group.

TABLE II. CODING OF RESPONSES REGARDING INFORMATION SEEKING AND ONLINE EXPLORATORY BEHAVIOR

\begin{tabular}{|c|c|c|}
\hline & Sighted & $\begin{array}{c}\text { Visually } \\
\text { Impaired }\end{array}$ \\
\hline Statement & $\%$ & $\%$ \\
\hline \multicolumn{3}{|l|}{$\begin{array}{l}\text { The approximate number of } \\
\text { websites I visit on a daily basis }\end{array}$} \\
\hline 0 & 5 & 0 \\
\hline 1 to 5 & 43 & 28 \\
\hline 6 to 10 & 47 & 28 \\
\hline 11 or more & 5 & 44 \\
\hline \multicolumn{3}{|l|}{$\begin{array}{c}\text { The number of NEW websites I } \\
\text { visit on a daily basis }\end{array}$} \\
\hline 0 & 33 & 20 \\
\hline 1 to 5 & 62 & 68 \\
\hline 6 to 10 & 5 & 12 \\
\hline 11 or more & 0 & 0 \\
\hline \multicolumn{3}{|l|}{ I avoid visiting new websites } \\
\hline True & 5 & 4 \\
\hline False & 95 & 96 \\
\hline \multicolumn{3}{|l|}{$\begin{array}{l}\text { I usually find new online content } \\
\text { like stories, videos and images } \\
\text { from }\end{array}$} \\
\hline A link from another website & 10 & 21 \\
\hline $\begin{array}{c}\text { Search engine like Google, } \\
\text { Yahoo and Bing }\end{array}$ & 52 & 66 \\
\hline Social networking websites & 33 & 13 \\
\hline Word of mouth & 5 & 0 \\
\hline $\begin{array}{l}\text { I don't know where I find } \\
\text { new website content }\end{array}$ & 0 & 0 \\
\hline
\end{tabular}


TABLE III. MEAN SCORES REgaRding SubJECTS' ONLINE EXPLORATORY BEHAVIOR, INFORMATION SEEKING AND WEB USAGE

\begin{tabular}{|c|c|c|c|c|c|c|}
\hline Statement & Mean & SD & $\mathbf{N}$ & t-test & df & $\mathbf{p}$ \\
\hline \multicolumn{7}{|c|}{ I frequently visit new websites } \\
\hline Visually Impaired & 3.76 & 1.20 & 25 & 1.37 & 44 & .176 \\
\hline Sighted & 3.29 & 1.10 & 21 & & & \\
\hline \multicolumn{7}{|c|}{ I have trouble finding my way around new websites } \\
\hline Visually Impaired & 3.04 & 1.33 & 24 & 1.60 & 43 & .116 \\
\hline Sighted & 2.43 & 1.21 & 21 & & & \\
\hline \multicolumn{7}{|c|}{$\begin{array}{l}\text { I avoid trying new websites because I am concerned about being able to find the information } \\
\text { that I am looking for }\end{array}$} \\
\hline Visually Impaired & 2.00 & 1.38 & 22 & 0.47 & 41 & .639 \\
\hline Sighted & 2.19 & 1.25 & 21 & & & \\
\hline \multicolumn{7}{|c|}{ I OFTEN have trouble finding what I am looking for online } \\
\hline Visually Impaired & 2.32 & 1.39 & 22 & 1.32 & 41 & .193 \\
\hline Sighted & 1.81 & 1.12 & 21 & & & \\
\hline \multicolumn{7}{|c|}{ I SOMETIMES have trouble finding what I am looking for online } \\
\hline Visually Impaired & 3.41 & 1.37 & 22 & 1.27 & 41 & .211 \\
\hline Sighted & 2.90 & 1.26 & 21 & & & \\
\hline \multicolumn{7}{|c|}{ Generally it is easy for me to find what I am looking for online } \\
\hline Visually Impaired & 4.41 & 0.80 & 22 & 0.78 & 41 & .437 \\
\hline Sighted & 4.19 & 1.03 & 21 & & & \\
\hline \multicolumn{7}{|c|}{ I am more comfortable visiting websites that I am familiar with } \\
\hline Visually Impaired & 4.22 & 1.11 & 22 & 2.13 & 41 & .039 \\
\hline Sighted & 3.57 & 0.87 & 21 & & & \\
\hline \multicolumn{7}{|c|}{ I wish the internet was easier to use } \\
\hline Visually impaired & 3.59 & 1.44 & 22 & 2.98 & 41 & .004 \\
\hline Sighted & 2.38 & 1.20 & 21 & & & \\
\hline \multicolumn{7}{|c|}{ Most websites are easy to navigate } \\
\hline Visually impaired & 3.86 & 1.04 & 22 & 1.05 & 41 & .298 \\
\hline Sighted & 4.14 & 0.65 & 21 & & & \\
\hline \multicolumn{7}{|c|}{ I enjoy using social networking websites } \\
\hline Visually impaired & 2.86 & 1.70 & 22 & 2.25 & 41 & .030 \\
\hline Sighted & 3.86 & 1.15 & 21 & & & \\
\hline \multicolumn{7}{|c|}{ I would like to use social networking websites but I find them too difficult to use } \\
\hline Visually impaired & 2.55 & 1.50 & 22 & 2.02 & 41 & .049 \\
\hline Sighted & 1.76 & 1.00 & 21 & & & \\
\hline
\end{tabular}


TABLE IV. RESPONSES RELATED TO WEBSITE USAGE

\begin{tabular}{|c|c|c|}
\hline & Sighted & $\begin{array}{c}\text { Visually } \\
\text { Impaired }\end{array}$ \\
\hline Statement & $\mathbf{\%}$ & $\mathbf{\%}$ \\
\hline $\begin{array}{c}\text { I normally visit this type of website } \\
\text { the most often }\end{array}$ & 0 & 4 \\
\hline Blogs & 0 & 0 \\
\hline Lifestyle Websites & 0 & 0 \\
\hline Medical Websites & 24 & 17 \\
\hline News Websites & 0 & 4 \\
\hline Online Encyclopedias & 19 & 25 \\
\hline Shopping Websites & $\mathbf{5 2}$ & $\mathbf{3 3}$ \\
\hline Social Networking Websites & 5 & 0 \\
\hline Sports Websites & 0 & 17 \\
\hline Other or I don't know & & \\
\hline $\begin{array}{c}\text { I normally have the most difficulty } \\
\text { using this type of website }\end{array}$ & $\mathbf{1 3}$ & $\mathbf{8}$ \\
\hline Blogs & 0 & 4 \\
\hline Lifestyle Websites & 0 & 0 \\
\hline Medical Websites & 0 & 13 \\
\hline News Websites & 0 & 0 \\
\hline Online Encyclopedias & 10 & 4 \\
\hline Shopping Websites & $\mathbf{5}$ & $\mathbf{2 1}$ \\
\hline Social Networking Websites & 5 & \\
\hline Sports Websites & 67 & \\
\hline $\begin{array}{c}\text { I don't have difficulty using } \\
\text { most websites }\end{array}$ & & \\
\hline
\end{tabular}

TABLE V. RESPONSES RELATED To SOCIAL NETWORKING WEBSITES

\begin{tabular}{|c|c|c|}
\hline & Sighted & $\begin{array}{c}\text { Visually } \\
\text { Impaired }\end{array}$ \\
\hline Statement & $\mathbf{\%}$ & $\mathbf{\%}$ \\
\hline $\begin{array}{c}\text { Do you have an account on a social networking } \\
\text { website? }\end{array}$ & & \\
\hline Yes & 95 & 67 \\
\hline No & $\mathbf{5}$ & $\mathbf{3 3}$ \\
\hline $\begin{array}{c}\text { Which social networking website do you visit } \\
\text { most often? }\end{array}$ & & \\
\hline Facebook & 81 & 67 \\
\hline Instagram & 0 & 4 \\
\hline LinkedIn & 0 & 8 \\
\hline Pinterest & 5 & 0 \\
\hline Twitter & $\mathbf{0}$ & $\mathbf{2 5}$ \\
\hline Other & 19 & 0 \\
\hline None & $\mathbf{5}$ & $\mathbf{2 9}$ \\
\hline
\end{tabular}

\section{CONCLUSION AND FUTURE WORK}

While the results of this pilot study indicate that Web accessibility generally may be improving, equivalent usability is still elusive. Findings at this stage of the research effort suggest that differences do exist between the online behavior of sighted users and users with visual impairments. These differences suggest that the presence of a visual impairment may have a significant impact on information seeking and online exploratory behavior. Most notably, the results of this study indicate that additional research is needed to explore the usability difficulties that users with visual impairments encounter on social networking websites specifically. Visually impaired participants indicated significant difficulties using websites of this type and were most severely challenged by social networking websites within the context of the options provided; findings mirrored by other studies [13]. This social networking usability issue is especially problematic as the use of these services has been shown to improve educational outcomes, promote self-esteem, enhance social inclusion and increase interpersonal relationships among other benefits [14$16]$.

While sighted users may capitalize on the aforementioned benefits with relative ease, the study suggests that individuals with visual impairments face substantial challenges in this regard. This is troubling in that studies show that users with visual impairments may benefit disproportionately from the benefits of these social networks [17]. Fears regarding diminished self-value, social stigmatization or negative selfimage related to the disability may be mitigated by the type of electronic social interaction that these online social networks facilitate $[18,19]$. Few studies however have addressed the participation, or lack thereof, of individuals with visual impairments in these online social networks and where this issue has been examined accessibility has been determined to be relatively poor $[13,20]$.

Moving forward a formal study of social network accessibility will be conducted applying the lessons learned from the initial investigative effort documented within this report. This study will utilize a combination of interview and observation techniques with the goal of collecting data with a greater level of detail. Information will also be collected regarding software (screen reader, Web browser, operating system) and device type; factors intentionally omitted from this initial investigation. This is significant given the increasing use of mobile screen reading technology by users with visual impairments [13] as mobile browsing increases in popularity [21].

\section{REFERENCES}

[1] A. Fernandes, F. Martins, H. Paredes and I. Pereira, "A Different Approach to Real Web Accessibility" in Proc. International Conference on Universal Access in Human-Computer Interaction, pp. 723-727, 2000.

[2] C. S. Fichten, J. V. Asuncion, M. Barile, V. Ferraro and J. Wolforth, "Accessibility of e-learning and computer and information technologies for students with visual impairments in postsecondary education," Journal of Visual Impairment and Blindness, vol. 103, pp. 543-557, Sep. 2009.

[3] K. Pernice and J. Nielsen, Beyond ALT Text: Making the Web Easy to User for Users with Disabilities. Fremont, CA: Nielsen Norman Group, 2001.

[4] H. Petrie, F. Hamilton and N. King, "Tension, what tension?: Website accessibility and visual design," In Proc. from the International CrossDisciplinary workshop on Web Accessibility, pp. 13-18, 2004.

[5] S. Harper, C. Goble and R. Stevens, "A Pilot Study to Examine the Mobility Problems of Visually Impaired Users Traveling the Web," ACM SIGCAPH Computers and the Physically Handicapped, vol. 68, pp. 10-19, Sep. 2000. 
[6] "Visual Impairment and Blindness - Fact Sheet," http://www.who.int/mediacentre/factsheets/fs282/en/, 2013.

[7] G. Brajnik, "Automatic web usability evaluation: what needs to be done?," In Proc. 6th Conference on Human Factors and the Web, 2000.

[8] S. Krug, Don't Make Me Think: A Common Sense Approach to Web Usability. 2nd ed. Berkeley, CA: New Riders Press, 2006.

[9] World Wide Web Consortium W3C, "Web Accessibility Initiative (WAI)," http://www.w3.org/WAI/intro/accessibility.php, 2010.

[10] International Organisation for Standardisation, ISO9241 Ergonomic, Part 11: Guidance on usability. Geneva, Switzerland, 1998.

[11] J. Lazar, J. H. Feng and H. Hochheiser, Research Methods in Human Computer Interaction. West Sussex, UK: Wiley Publishing,, 2010.

[12] K. L. Wuensch, "What is a Likert Scale and How Do You Pronounce Likert?," Retrieved Feb 12, 2013 from http://core.ecu.edu/psyc/wuenschk/StatHelp/Likert.htm, 1998.

[13] "Web Accessibility in Mind. Screen Reader User Survey 4," http://webaim.org/projects/screenreadersurvey4/\#mobil, 2013.

[14] P. Collin, K. Rahilly, I. Richardson and A. Third. The Benefits of Social Networking Services. Abbotsford, Australia : Cooperative Research Centre for Young People, Technology and Well Being, 2010.
[15] K. N. Hampton, L. S. Goulet, L. Rainie and K. Purcell, Social networking sites and our lives. Washington, DC : Pew Research Center, 2011.

[16] D. M. Boyd, Why Youth (Heart) Social Network Sites: The Role of Networking Publics in Teenage Social Life. Cambridge, MA : MIT Press, 2007.

[17] S. M. Kelly and T. J. Smith, "The digital social interactions of students with visual impairments: findings from two national surveys," Journal of Visual Impairment \& Blindness, vol. 102, pp. 528-539, Sep 208.

[18] S. Kef, J. J. Hox and H. T. Habekothe, "Social networks of visually impaired and blind adolescents. Structure and effect on well-being," Social Networks, vol. 22, pp. 73-91, May 2000.

[19] F. Fovet, "Impact of the use of Facebook Amongst Students of High School Age with Social, Emotional and Behavioral Difficulties (SEBD)," In Proc. from the 39th IEEE Frontiers in Education Conference, pp. 1-6, 2009.

[20] Accessibility of Social Networking Services. Madrid, Spain: Observatory on ICT Accessibility - Discapnet, 2010.

[21] "Statcounter global stats: Mobile vs. desktop from Jan. 2009 to Apr. 2013," http://gs.statcounter.com/\#mobile_vs_desktop-ww-monthly200901-201304, 2013. 